\title{
Nanolayers of Lead Selenide on Potassium Chloride Substrates: Specific Features of Formation
}

\author{
Arif M. Pashaev ${ }^{1}$, Omar I. Davarashvili ${ }^{2}$, Megi I. Enukashvili ${ }^{2}$, Zaira G. Akhvlediani ${ }^{2,3}$, Revaz G. Gulyaev ${ }^{2}$ and \\ Vladimir P. Zlomanov ${ }^{4}$ \\ 1. National Aviation Academy of Azerbaijan, Baku AZ-1045, Azerbaijan \\ 2. Iv. Javakhishvili Tbilisi State University, Tbilisi 0128, Georgia \\ 3. E. Andronikashvili Institute of Physics, Tbilisi 0186, Georgia \\ 4. M.V. Lomonosov Moscow State University, Moscow 119899, Russia
}

Received: February 15, 2013 / Accepted: March 16, 2013 / Published: April 25, 2013.

\begin{abstract}
The article deals with the character of growth of $\mathrm{PbSe}$ layers on $\mathrm{KCl}$ substrates. Two stages of growth differing greatly in the rate were revealed. It is shown that the rate-rate ratio between the first and second stages hardly changes when the growth conditions change. The tangential lattice constants were used for determination of deformations in the layers, and they were measured over a wide range of layers thickness. At the layers thickness $<100 \mathrm{~nm}$, the tangential lattice constant depends on the growth rate rather slightly, while, at the thickness 100 to $200 \mathrm{~nm}$, the dependence of the tangential lattice constant on the growth rate passes a peak.
\end{abstract}

Key words: Tangential lattice constant, layer thickness, relative deformation-mismatch, growth rate, residual deformation.

\section{Introduction}

Usually they associate nanotechnologies in semiconductors with quantum structures in the layers. In the majority of semiconductors, conditions of their realization are for the thickness of layers less than 100 nm. At such thickness, there emerges dimensional quantization which affects significantly the redistribution of current carriers in allowed bands and the properties of corresponding structures and devices.

At nanothickness of the layers, deformation effects are revealed in semiconductors as well. In this case, because of the shift in the edges of conductivity and valence bands, even more significant changes can be observed in the energy spectrum. In particular, deformation effects in the layers of IV-VI semiconductors are revealed when they grow on dielectric substrates $\mathrm{KCl}, \mathrm{NaCl}, \mathrm{BaF}_{2}$ and other at

Corresponding author: Omar I. Davarashvili, Dr. Sci., professor, research fields: material science, physics of semiconductors and lasers. E-mail: omardavar@yahoo.com. significant mismatch $[1,2]$.

This work deals with new specific features of the formation of $\mathrm{PbSe}$ nanolayers grown on the $\mathrm{KCl}$ substrate which lead to the achievement of higher deformations (strains) at as high thickness values of the layers as possible.

\section{Experiments}

The epitaxial $\mathrm{PbSe}$ layers were grown of the $\mathrm{KCl}$ substrates (100) by the method of molecular epitaxy with a "hot wall". The substrate temperature was in the range from 240 to $320^{\circ} \mathrm{C}$, while the temperature of the source, polycrystalline $\mathrm{PbSe}$, was in the range from 450 to $510^{\circ} \mathrm{C}$. The temperature of the walls of the quartz ampule exceeded the temperature of the source by $1-2{ }^{\circ} \mathrm{C}$. Besides the temperature of the epitaxy source, the rate of inflow of the evaporated molecules onto substrate changed under variations in the distance from the open end of the ampule with the epitaxy source to the substrate over the range from 1 
to $12 \mathrm{~mm}$. The layers thicknesses were determined by the relation between the intensities of X-ray reflection from the clean substrate and from the substrate with the layer. In order to exclude the intensity of incident $\mathrm{X}$-ray radiation (its possible fluctuations), the intensity ratios from two crystallographic planes, for example, (200) and (400) were determined.

The tangential lattice constant was determined by the interplane distance $d=\lambda / 2 \sin \theta$ at the reflection from plane (400):

$$
a=\frac{\lambda}{2 \sin \theta} \sqrt{h^{2}+k^{2}+l^{2}}=\frac{2 \lambda}{\sin \theta}
$$

\section{Results and Discussion}

Fig. 1 shows the dependences of layers thickness on the growth time for two cases: a is the distance between the open edge of the ampule with epitaxy source and the substrate is equal to $1 \mathrm{~mm}$, and the substrate temperature makes up $240{ }^{\circ} \mathrm{C}$; b is the same distance is equal to $12 \mathrm{~mm}$, and the substrate temperature makes up $300^{\circ} \mathrm{C}$.

A specific feature of these dependences is a "delay" in the beginning of epitaxy and subsequent rapid growth of layers thickness with time. Comparing these results with the data given in works [3, 4], it was revealed that the first interval assumed to be a delay in growth actually was a significantly slow process of nucleation and merging of islands-nuclei. It is of prime importance that, at the first stage, the layers thickness made up $\sim 10 \mathrm{~nm}$, which corresponded to the $\mathrm{X}$-ray range sensitivity. In this case, at the first stage with consideration for the delay time the growth time made up 9 s (Fig.1, Curve a) and $60 \mathrm{~s}$ (Fig. 1, Curve b) and the growth rate made up (a) $1 \mathrm{~nm} / \mathrm{s}$ and (b) 0.17 $\mathrm{nm} / \mathrm{s}$. At the second stage, rapid layer-by-layer growth took place and the growth rate varied within the ranges of (a) $1-25 \mathrm{~nm} / \mathrm{s}$ and (b) $3-6 \mathrm{~nm} / \mathrm{s}$. The difference in the growth rates in both cases is determined by different rates of delivery of evaporated molecules to the substrate. The ratio of maximum growth rates at the second and first stages is the same

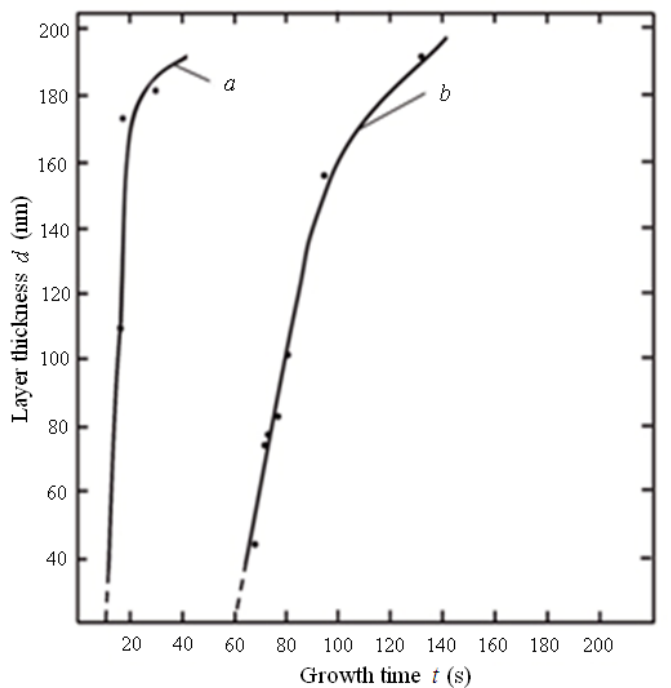

Fig. 1 Dependence of the thickness of epitaxial PbSe layers on the growth time at the distance between the open end of the ampule with the source of epitaxy and the substrate: (a) $1 \mathrm{~mm}$ and (b) $12 \mathrm{~mm}$.

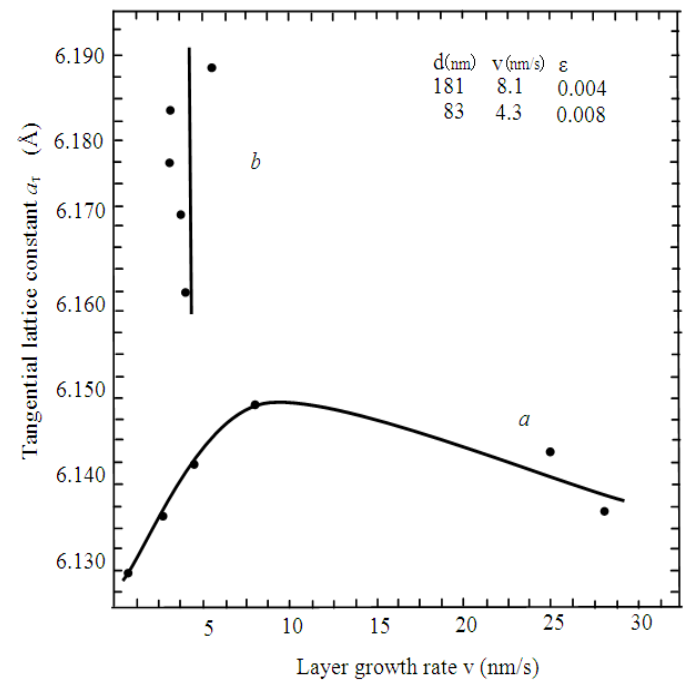

Fig. 2 Dependence of the tangential lattice constant on the growth rate at the second stage (a) at the thickness of layers $100-200 \mathrm{~nm}$ and (b) at the thickness of layers $<100 \mathrm{~nm}$.

for cases $\mathrm{a}$ and $\mathrm{b}$ in Fig. 1 and is equal to $\sim 25$.

The data on the total growth rate, the growth rate at the second stage along with the growth conditions and tangential lattice constants are listed in the Table. These data confirms the fact that with the increasing layers thickness, the relaxation of the elastic energy of the layers increases also. At the layer thickness equal to $\sim 50 \mathrm{~nm}$, the deformation in the layers makes up $\sim 0.01[5-7]$. 
Table 1 Data on growth conditions, thickness, tangential lattice constants and growth rates of epitaxial PbSe layers 100-200 $\mathrm{nm}$ thick (1-6) and < $100 \mathrm{~nm}$ thick (7-10).

\begin{tabular}{llllllllll}
\hline No. Layer & $\begin{array}{l}\text { Temperature } \\
\text { of the } \\
\text { substrate } T \\
\left({ }^{\circ} \mathrm{C}\right)\end{array}$ & $\begin{array}{l}\text { Temperature } \\
\text { of the source } \\
T\left({ }^{\circ} \mathrm{C}\right)\end{array}$ & $\begin{array}{l}\text { Growth } \\
\text { time } t(\mathrm{~s})\end{array}$ & $\begin{array}{l}\text { Layer } \\
\text { thickness } \\
d(\mathrm{~nm})\end{array}$ & $\begin{array}{l}\text { Tangential } \\
\text { lattice } \\
\text { constant } a_{\tau} \\
(\AA)\end{array}$ & $\begin{array}{l}\text { Total layer } \\
\text { growth rate } \\
v(\mathrm{~nm} / \mathrm{s})\end{array}$ & $\begin{array}{l}\text { Growth rate of } \\
\text { the layers at the } \\
\text { second stage } v \\
(\mathrm{~nm} / \mathrm{s})\end{array}$ & $\begin{array}{l}\text { Relative } \\
\text { deformation- } \\
\text { mismatch }\end{array}$ \\
\hline 1 & SL-277 & 240 & 470 & 30 & 181 & $6.149(9)$ & 6 & 8.1 & 0.37 \\
2 & SL-284 & 240 & 470 & 15 & 175 & $6.136(7)$ & 11.7 & 27.5 & 0.17 \\
3 & SL-283 & 240 & 470 & 13 & 110 & $6.144(4)$ & 8.5 & 25 & 0.33 \\
4 & SL-215 & 240 & 450 & 300 & 200 & $6.129(7)$ & 0.7 & 0.8 & 0.07 \\
5 & SL-216 & 240 & 450 & 130 & 193 & $6.136(4)$ & 1.5 & 2.6 & 0.17 \\
6 & SL-237 & 280 & 470 & 90 & 157 & $6.142(1)$ & 1.8 & 4.9 & 0.27 \\
7 & SL-241 & 300 & 470 & 80 & 101 & $6.162(0)$ & 1.3 & 4.5 & 0.59 \\
8 & SL-258 & 300 & 470 & 77 & 83 & $6.172(1)$ & 1.1 & 4.3 & 0.75 \\
9 & SL-251 & 320 & 470 & 78 & 72 & $6.175(4)$ & 1.0 & 3.5 & 0.80 \\
10 & SL-255 & 300 & 470 & 78 & 68 & $6.177(4)$ & 0.9 & 3.2 & 0.83 \\
11 & SL-262 & 300 & 470 & 67 & 52 & $6.188(4)$ & 0.7 & 6 & 1.0 \\
\hline
\end{tabular}

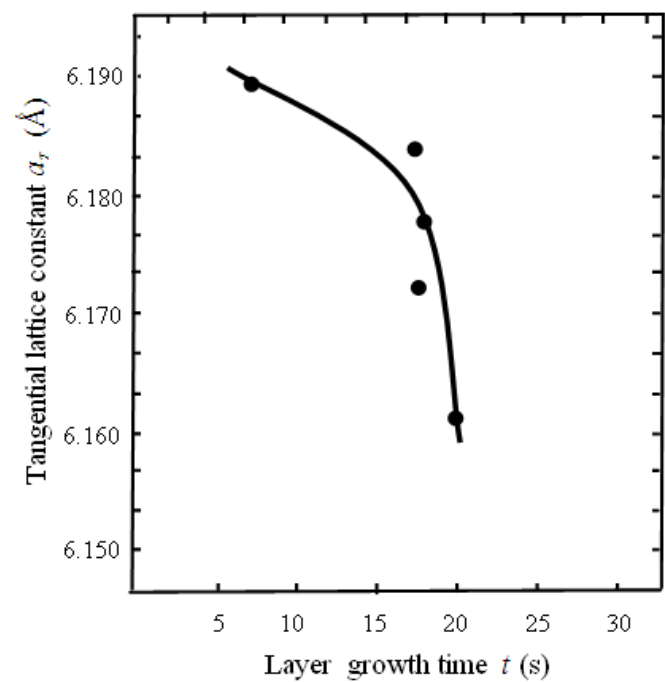

Fig. 3 Dependence of the tangential lattice constant on the growth time at the second stage and at the thickness of layers $<100 \mathrm{~nm}$.

Fig. 2 shows the dependence of the tangential lattice constant on the growth rate at the second stage for the layers of the thickness of (a) 100-200 nm thick and (b) $<100 \mathrm{~nm}$. These data follow from the investigation results given in the Table.

In accordance of the mechanism of formation of residual elastic deformations in strained PbSe layers, nonstoichiometric defects were efficiently placed in the nuclei of dislocations especially at the layers thickness $<100 \mathrm{~nm}$ and retarded their movement. In the result, the elastic energy of layers did not relax signficantly, and the tangential lattice constant increased [8]. In the layers 100-200 nm thick, the elastic energy was so high that the nonstoichiometric defects could not retard the dislocations, and the relaxation of strains increased just at low growth rates.

The increase in the tangential lattice constant at relatively low growth rates is associated with the fact that the growth rate was higher than that of penetration of dislocations into the layer from the substrate. The peak in this dependence is the result of formation of the disordered state at high growth rates.

The data presented in Fig. 2 suggests an idea that for revealing the details of layers' growth and achievement of the maximal tangential lattice constant is advisable to correlate growth time of the layers with its rate. As is seen from Fig. 2 for the thickness of layers $<100 \mathrm{~nm}$ and in the limit of growth rates $3.5-6 \mathrm{~nm} / \mathrm{s}$ it would be more useful to study the dependence of the tangential lattice constant on growth time (Fig. 3). Apparently, the rate of arrangement of defects in the nuclei of dislocations is much less than $3.5 \mathrm{~nm} / \mathrm{s}$. Therefore, when growth time increases more dislocations are without retarding and elastic energy of layers relaxes quicker. 


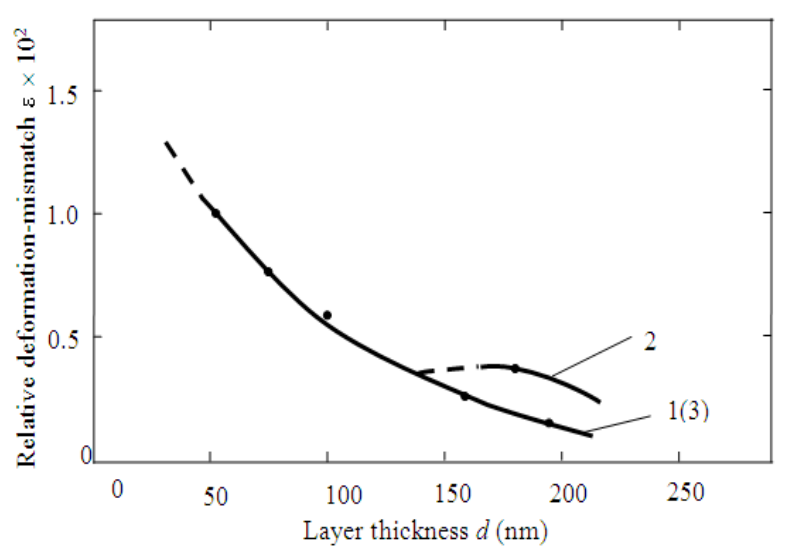

Fig. 4 Dependence of the deformation-mismatch in epitaxial PbSe layers on the layers thickness (in the range of $100-200 \mathrm{~nm}$ ) at growth rates at the second stage: (1) $1 \mathrm{~nm} / \mathrm{s}$; (2) $8 \mathrm{~nm} / \mathrm{s}$ and (3) $>20 \mathrm{~nm} / \mathrm{s}$.

The dependence of relative deformation-mismatch on the layers thickness at different growth rates was constructed (Fig. 4) and it represents the development of the data shown in Fig. 2. As the growth rate increased $\sim 8$ times, the deformation increased two-fold in the thickness range of 100-200 nm. It should be noted that, at high growth rates, the layers $<$ $100 \mathrm{~nm}$ thick were not uniform.

\section{Conclusions}

The investigation of thin strained PbSe layers $(d<$ $200 \mathrm{~nm}$ ) produced by molecular epitaxy with a "hot wall" revealed that the growth of the layers proceeded in two stages and that their growth rate depended on that of delivery of evaporated molecules to the substrate.

The residual deformation determined in terms of tangential lattice constants made up $\sim 0.01$ in the layers $<100 \mathrm{~nm}$ thick, hardly depended on the growth rate $<6 \mathrm{~nm} / \mathrm{s}$ and changed more clearly with decreasing of the growth time. In the layers 100-200 $\mathrm{nm}$ thick, the maximum deformation made up $\sim 0.004$ at the growth rate of $8-10 \mathrm{~nm} / \mathrm{s}$.

\section{References}

[1] A.M. Pashaev, O.I. Davarashvili, M.I. Enukashvili, Z.G. Akhvlediani, R.G. Gulyaev, V.P. Zlomanov, Growth and properties of strained epitaxial nanolayers of lead selenide, in: Book of Abstracts of the International Conference on Functional Materials and Nanotechnologies, Riga, 2012, p. 198.

[2] A.M. Pashaev, O.I. Davarashvili, M.I. Enukashvili, Z.G. Akhvlediani, R.G. Gulyaev, V.P. Zlomanov, Unrelaxed state in epitaxial heterostructures based on lead selenide, J. Modern Phys. 3 (6) (2012) 502-510.

[3] L.S. Palatnik, R.K. Sorokin, L.P. Zozulya, The Mechanism of Growth of Isolated Particles at Epitaxy of Lead Chalcogenides on $\mathrm{NaCl}$ and $\mathrm{KC} 1$, Solid State Phys. 11 (5) (1969) 1265-1270.

[4] O.P. Pchelyakov, Yu.B. Bolkhovityanov, A.V. Dvurechenskii, L.V. Sokolov, A.I. Nikiforov, A.I. Yakimov, et al., Silicon-germanium nanostructures with quantum dots: Formation mechanism and electrical properties, Phys. Tech. Semicon. 34 (11) (2000) 1281-1299.

[5] A.M. Pashaev, O.I. Davarashvili, Z.G. Akhvlediani, M.I. Enukashvili, L.P. Bychkova, M.A. Dzagania, Study on the forbidden gap width of strained epitaxial lead selenide layers by optical transmission, J. Mat. Sci. Eng. 2 (2) (2012) 142-150.

[6] A.M. Pashaev, O.I. Davarashvili, M.I. Enukashvili, R.G. Gulyaev, M.A. Dzagania. Analysis of the conditions of growth and the properties of epitaxial layers of lead selenide in connection with realization in them of high effective "negative" pressure, Trans. Nat. Acad. Sci. Georg. 38 (1) (2012) 31-35.

[7] A.M. Pashaev, O.I. Davarashvili, M.I. Enukashvili, Z.G. Akhvlediani, R.G. Gulyaev, L.P. Bychkova, Epitaxial lead selenide layers over a wide range of their thickness on dielectric substrates, J. Mat. Sci. Eng. 3 (2) (2013) 97-103.

[8] A.M. Pashaev, O.I. Davarashvili, Z.G. Akhvlediani, M.I. Enukashvili, R.G. Gulyaev, V.P. Zlomanov. The structure of thin epitaxial layers of lead selenide, J. Mat. Sci. Eng. 3 (2) (2013) 117-122. 